05,06

\title{
Амплитудные зависимости диэлектрических потерь в тонкопленочном наногранулированном композите $(x) \mathrm{Ni}-(1-x) \mathrm{PZT}$
}

\author{
(C) А.В. Калгин ${ }^{1,2}$, И.Ю. Кобяков ${ }^{1}$ \\ ${ }^{1}$ Воронежский государственный технический университет, \\ Воронеж, Россия \\ ${ }^{2}$ Воронежский государственный университет, \\ Воронеж, Россия \\ E-mail: kalgin_alexandr@mail.ru \\ Поступила в Редакцию 27 января 2021 г. \\ В окончательной редакции 27 января 2021 г. \\ Принята к публикации 30 января 2021 г.
}

При температурах $T$ ниже сегнетоэлектрической точки Кюри и разных напряженностях постоянного электрического поля $E_{=}$изучены зависимости диэлектрических потерь $\operatorname{tg} \delta$ в тонкопленочном наногранулированном композите $(x) \mathrm{Ni}-(1-x)\left[\mathrm{Pb}_{0.81} \mathrm{Sr}_{0.04}\left(\mathrm{Na}_{0.5} \mathrm{Bi}_{0.5}\right)_{0.15}\right]\left[\left(\mathrm{Zr}_{0.575} \mathrm{Ti}_{0.425}\right)\right] \mathrm{O}_{3}$ от напряженности переменного электрического поля $E_{\sim}$. Обнаружено, что $\operatorname{tg} \delta$ практически не изменяется с ростом $E_{\sim}$ до напряженности некоторого порогового поля $E_{t}$ и плавно возрастает при $E_{\sim}>E_{t}$. Величина $E_{t}$ уменьшается, когда $T$ увеличивается, а $x$ и $E_{=}$уменьшаются. Обнаруженные зависимости $\operatorname{tg} \delta\left(E_{\sim}\right)$ и $E_{t}$ от $T, x$ и $E_{=}$ объясняются в рамках модели взаимодействия доменных границ с закрепляющими их точечными дефектами в сегнетоэлектриках.

Ключевые слова: магнитоэлектрический композит, точечный дефект, доменная граница, диэлектрические потери, точка Кюри.

DOI: 10.21883/FTT.2021.06.50934.012

\section{1. Введение}

Бурно развивающаяся современная электронная техника предъявляет повышенные требования к используемым материалам. Оказывается, что в своем большинстве природные материалы уже не в состоянии удовлетворить растущие функциональные и эксплуатационные требования. Повсеместному их внедрению препятствует ограниченность диапазона рабочих параметров, отсутствие перекрестных эффектов и невозможность изменения функциональных и эксплуатационных параметров. Это послужило стимулом разрабатывать и осваивать новые материалы. Возрастающие тенденции современной электроники к миниатюризации электронных устройств и повышения их функциональных возможностей, а также успехи нанотехнологий [1,2] последних десятилетий привели к созданию искусственных наноматериалов. Особенностью таких материалов является возможность обеспечивать качественно новые функциональные и/или ранее недостижимые эксплуатационные показатели, которые могут изменяться в достаточно широких пределах при изменении внутренних параметров и внешних воздействий.

Среди искусственных наноматериалов значительное место занимают наногранулированные композитные среды ферромагнетик-сегнетоэлектрик, отличающиеся способностью взаимно преобразовывать магнитные и электрические поля за счет перекрестных взаимодействий (магнитоэлектрический эффект) [3,4].
Магнитоэлектрический (МЭ) эффект в композитах в значительной степени определяется процессами, связанными с состоянием и динамикой доменной структуры $[5,6]$. Эти процессы ответственны за величины и нелинейность МЭ-коэффициентов и существенно зависят от температуры, характера взаимодействия доменных границ с дефектами кристаллической решетки, концентрации дефектов.

Вместе с тем ценная информация о динамике доменных границ может быть получена из измерений амплитудных зависимостей диэлектрических потерь, когда амплитуда переменного электрического поля изменяется в широких пределах $[7,8]$. Поле приводит к колебанию доменных границ относительно „точек закрепления“, каковыми являются точечные дефекты. Если амплитуда поля достаточно велика, то происходит отрыв доменных границ от стопоров, сопровождающийся, как правило, резким увеличением диэлектрических потерь.

Следовательно, изучение проблемы движения доменных границ в МЭ-композитах методом диэлектрической спектроскопии представляет собой важную физическую задачу.

По проблеме динамики доменных границ выполнено большое количество теоретических и экспериментальных работ. Однако объектами исследований этих работ в основном служили ферромагнетики $[9,10]$ и сегнетоэлектрики $[11,12]$, тогда как МЭ-композитам, имеющим большой практический потенциал [3], не уделялось должного внимания. 


\begin{abstract}
Поэтому целью настоящей работы являлось изучение амплитудных зависимостей диэлектрических потерь в наногранулированном ферромагнетик-сегнетоэлектрическом композите $(x) \mathrm{Ni}-(1-x)\left[\mathrm{Pb}_{0.81} \mathrm{Sr}_{0.04}\left(\mathrm{Na}_{0.5} \mathrm{Bi}_{0.5}\right)_{0.15}\right]\left[\left(\mathrm{Zr}_{0.575} \mathrm{Ti}_{0.425}\right)\right] \mathrm{O}_{3}$ (далее $(x) \mathrm{Ni}-(1-x) \mathrm{PZT})$ при разных температурах и напряженностях переменного электрического поля, а также модельное описание полученных экспериментальных данных.
\end{abstract}

\section{2. Методика измерений и образцы}

Образцы композита $(x) \mathrm{Ni}-(1-x) \mathrm{PZT}$ получали ионно-лучевым распылением составной мишени на кремниевую, хлорид-натриевую и ситалловую подложки в атмосфере аргона при давлении $6.2 \cdot 10^{-4} \mathrm{~Pa}$. Мишень представляла собой никелевую основу размерами $280 \times 80 \times 10 \mathrm{~mm}$ с закрепленными на ее поверхности девятнадцатью керамическими пластинами $\left[\mathrm{Pb}_{0.81} \mathrm{Sr}_{0.04}\left(\mathrm{Na}_{0.5} \mathrm{Bi}_{0.5}\right)_{0.15}\right]\left[\left(\mathrm{Zr}_{0.575} \mathrm{Ti}_{0.425}\right)\right] \mathrm{O}_{3}$ (далее $\mathrm{PZT}$ ) размерами $80 \times 10 \times 2 \mathrm{~mm}$. Расстояние между пластинами изменялось от $0 \mathrm{~mm}$ на одном краю мишени до $16 \mathrm{~mm}$ на другом, что позволяло получать композит с содержанием металлической фазы $x$ от 2 до 59 at.\%. В настоящей работе для исследований использовались образцы композита с $x=0,0.02,0.05,0.07,0.1$ и 0.3 .

Композит на кремниевой, хлорид-натриевой и ситалловой подложках использовали для рентгеноструктурных, электронно-микроскопических и диэлектрических исследований соответственно. Кремниевые подложки, благодаря малому числу рентгеновских рефлексов от нее, применялись для упрощения расшифровки рентгенограммы для образца композита. Хлорид-натриевые подложки использовалась благодаря возможности их растворения в дистиллированной воде, что позволяло изучать в электронном микроскопе морфологию композитных пленок на просвет. Ситалловые подложки, в отличие от кремниевых и хлорид-натриевых подложек, имеют низкую стоимость, вследствие чего для экспериментов в основном изготавливались образцы на их основе.

Чтобы измерить тангенс угла диэлектрических потерь в композите, создавалась многослойная структура в виде ситалловой подложки с последовательно напыленными на ее поверхность слоями металлов $\mathrm{Cr}-\mathrm{Cu}-\mathrm{Cr}$ и, используя специальную маску, композитной пленкой, на поверхности которой формировалась контактная площадка в виде слоя сусального серебра. Слои $\mathrm{Cr}$ позволяли улучшить адгезию композитной пленки и предотвратить окисление $\mathrm{Cu}$. Электрический контакт зондов из бериллиевой бронзы к поверхностям пленки осуществлялся через слой $\mathrm{Cr}$, располагающийся над слоем $\mathrm{Cu}$ под пленкой, и контактную площадку. Композитные пленки имели форму диска с диаметром $6 \mathrm{~mm}$ и толщиной от 0.03 до $0.6 \mu \mathrm{m}$ в зависимости от взаимного расположения мишени и подложки, а ситалловые подложки - форму прямоугольника с геометрическими размерами $8 \times 8 \times 0.6 \mathrm{~mm}$.

Толщина композитных пленок измерялась на интерферометре МИИ-4. Состав композита определялся с помощью электронно-зондового рентгеновского микроанализатора JXA-8200. Рентгеноструктурный анализ проводился посредством дифрактометра Bruker D2 Phaser с использованием $\mathrm{Cu} K_{\alpha}$-излучения, электронно-микроскопические исследования осуществлялись с использованием просвечивающего электронного микроскопа Libra 120, а для измерения тангенса угла диэлектрических потерь применялся измеритель иммитанса Е7-20.

Ошибка измерений тангенса угла диэлектрических потерь составляла не более 5\%. Температура измерялась хромель-алюмелевой термопарой с погрешностью не более $\pm 0.5 \mathrm{~K}$.

\section{3. Результаты и обсуждение}

Электронно-микроскопические исследования (рис. 1) выявили у пленки композита $(x) \mathrm{Ni}-(1-x) \mathrm{PZT}$ с $x=0.3$ сложную лабиринтоподобную структуру, в которой темные области, отвечающие металлическим гранулам $\mathrm{Ni}$ со средним размером около $2 \mathrm{~nm}$, случайным образом распределены на светлом фоне, соответствующем диэлектрической матрице PZT.

Рентгеноструктурный анализ подтвердил наличие в композите только двух фаз: Ni и PZT (рис. 2,a).

Виден широкий максимум, относящийся к аморфному PZT, и несколько острых пиков, соответствующих кристаллическим Ni и Si. Рефлексы Si соответствуют кремниевой подложке, на которой напылен композит. Никаких посторонних фаз не было обнаружено.

Следовательно, на основе электронно-микроскопических и рентгеноструктурных исследований можно сделать

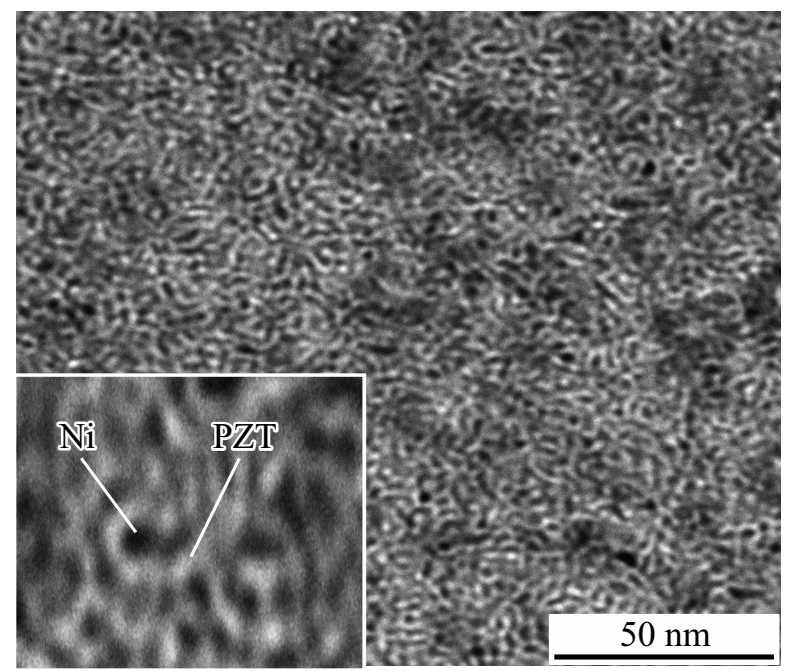

Рис. 1. Морфология пленки композита $(x) \mathrm{Ni}-(1-x) \mathrm{PZT}$ c $x=0.3$, полученная с использованием просвечивающей электронной микроскопии. 

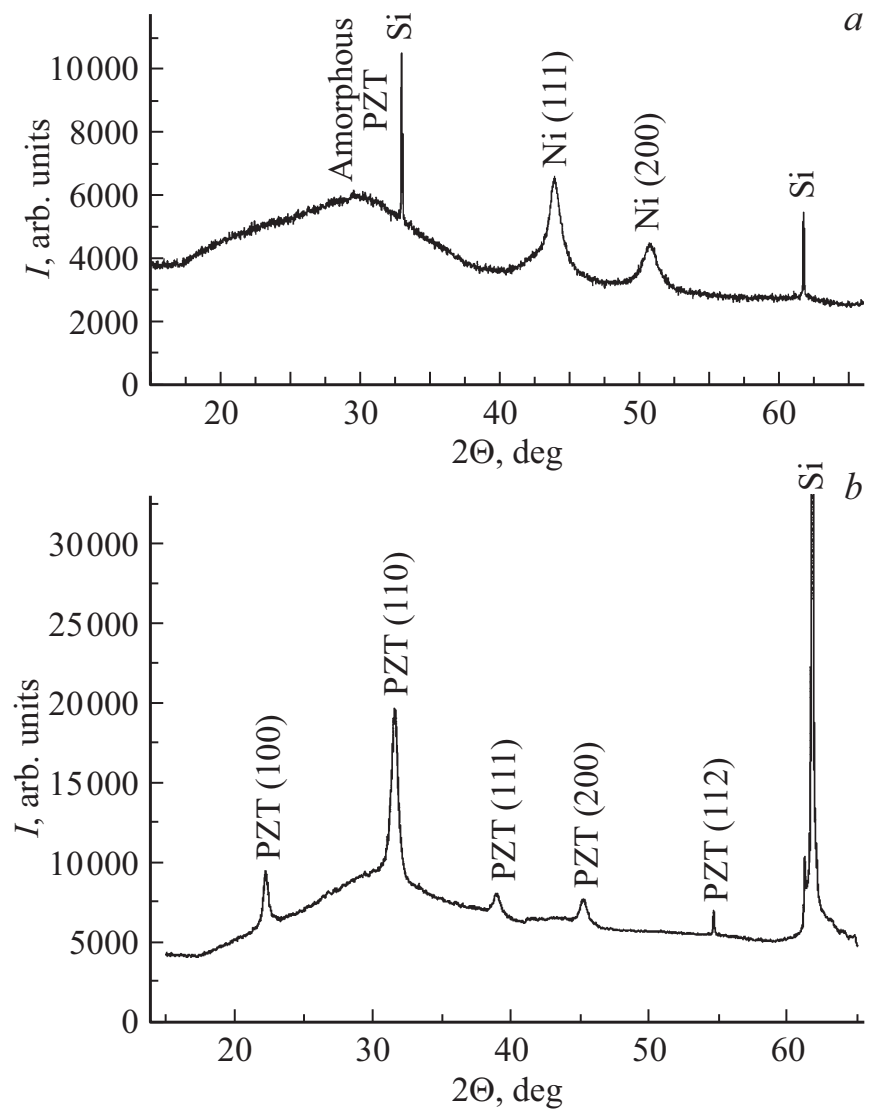

Рис. 2. Рентгенограммы для неотожженного образца с $x=0.3(a)$ и отожженного образца с $x=0$ на монокристаллической кремниевой подложке с ориентацией $\langle 100\rangle$ при комнатной температуре.

вывод о том, что в результате ионно-лучевого распыления был получен наногранулированный композит, а не твердый раствор.

Однако аморфный PZT не обладает сегнетоэлектрическими свойствами и поэтому не может использоваться для изучения динамики доменных границ. Для изучения динамики доменных границ в PZT необходимо матрицу композита перевести из аморфного состояния в кристаллическое, то есть подвергнуть термической обработке выше температуры кристаллизации $\left(670^{\circ} \mathrm{C}[13]\right)$. В результате проведенных рентгеноструктурных исследований образцов $(x) \mathrm{Ni}-(1-x) \mathrm{PZT}$ с $x=0,0.02,0.05$, 0.07, 0.1 после отжига в разных условиях выбран оптимальный режим термической обработки: постепенное нагревание от комнатной температуры до $700^{\circ} \mathrm{C}$ в течение $1 \mathrm{~h} \mathrm{c}$ последующим медленным охлаждением до комнатной температуры. Рентгенограмма для образца с $x=0$, отожженного в оптимальном режиме, показана на рис. 2, $b$.

Для отожженных композитных пленок, согласно цели работы, были изучены зависимости тангенса угла диэлектрических потерь $\operatorname{tg} \delta$ от напряженности перемен- ного электрического поля $E_{\sim}$ при температурах $T$ ниже сегнетоэлектрической точки Кюри (рис. 3).

На зависимостях можно выделить два участка: амплитудно-независимый (I) и амплитудно-зависимый (II). Переход от одного участка к другому происходит при поле $E_{t}$, которое носит название порогового [14] и соответствует точке пересечения двух прямых линий, аппроксимирующих кривую $\operatorname{tg} \delta\left(E_{\sim}\right)$. Видно, что с ростом температуры уровень кривой на участке I и крутизна кривой на участке II увеличиваются, а величина $E_{t}$ уменьшается.

Поскольку композит состоит в основном из сегнетоэлектрической фазы PZT, а для полидоменных сегнетоэлектрических кристаллов в измерительных полях диэлектрические параметры обусловлены движением доменных границ $[7,8,12,14,15]$, то обнаруженные амплитудные зависимости могут быть объяснены в рамках доменного механизма диэлектрических потерь в PZT. Согласно этому механизму, в отсутствие переменного электрического поля $E_{\sim}$ сегнетоэлектрические доменные границы в композите находятся в равновесных положениях. Под действием поля $E_{\sim}$ доменные границы смещаются из положения равновесия, приводя к увеличению свободной энергии РZТ вследствие взаимодействия доменных границ с различными дефектами. Когда $E_{\sim}<E_{t}$, в PZT происходит упругое смещение доменных границ относительно центров закрепления (дефектов), сопровождающееся диэлектрическими потерями тем большими, чем больше $E_{\sim}$ (участок I). После снятия поля доменные границы возвращаются в прежнее положение. В поле $E_{\sim}=E_{t}$ начинается процесс отрыва доменных границ от центров закрепления с последующим их необратимым смещением. Этот процесс при $E_{\sim}>E_{t}$ носит лавинообразный характер и в нем участвует значительно большее число доменов, чем на

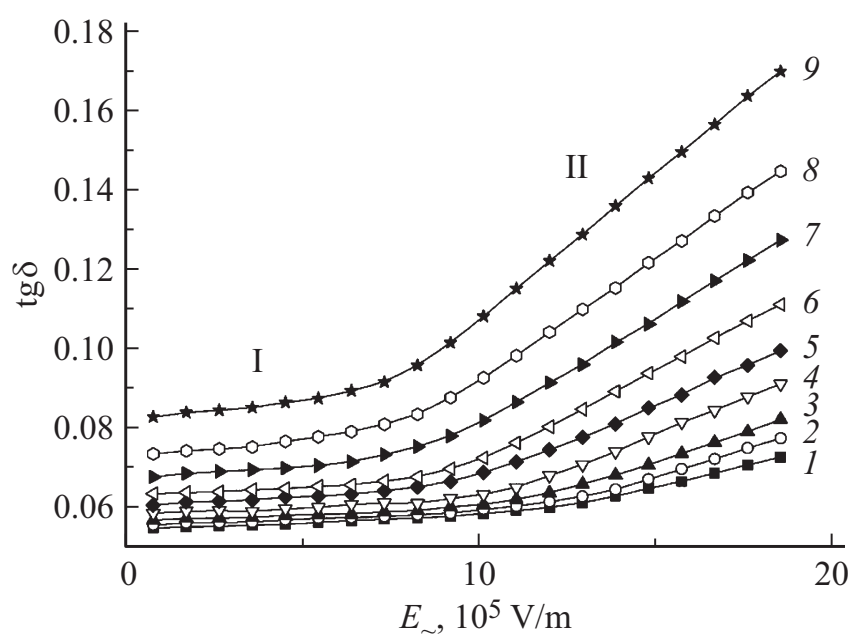

Рис. 3. Амплитудные зависимости $\operatorname{tg} \delta$ для образца композита $(x) \mathrm{Ni}-(1-x) \mathrm{PZT}$ с $x=0.05$ при частоте $1 \mathrm{kHz}$ и разных температурах $T,{ }^{\circ} \mathrm{C}: 1-20,2-50,3-80,4-110$, $5-140,6-170,7-200,8-230,9-260$. 


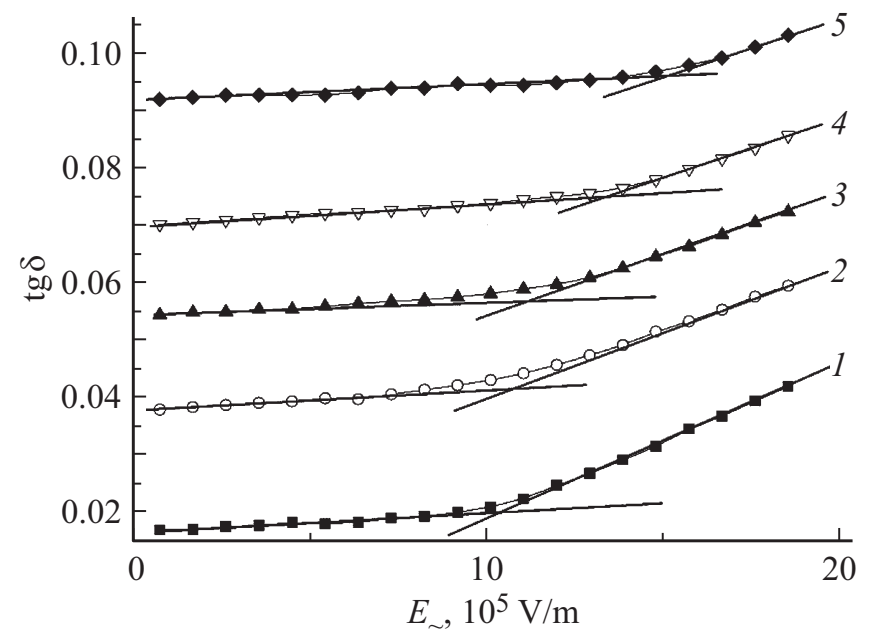

Рис. 4. Амплитудные зависимости $\operatorname{tg} \delta$ при частоте $1 \mathrm{kHz}$ и температуре $20^{\circ} \mathrm{C}$ для образцов композита $(x) \mathrm{Ni}-(1-x) \mathrm{PZT}$ с разным $x: 1-0,2-0.02,3-0.05,4-0.07,5-0.1$.

участке I, смещение идет более интенсивно и кривая потерь становится круче (участок II). С температурой $T$ число смещающихся доменов и интенсивность их движения возрастают, что сказывается на росте $\operatorname{tg} \delta$ во всем интервале измерительных полей $(0.7-18.5) \cdot 10^{5} \mathrm{~V} / \mathrm{m}$. При этом уменьшается величина порогового поля $E_{t}$, так как тепловое поле способствует ослаблению силы связи между доменными границами и центрами закрепления.

Зависимости, подобные тем, что продемонстрированы на рис. 3, были выявлены для образцов композита с $x=0,0.02,0.07$ и 0.1. Сопоставление этих зависимостей показало повышение уровня кривых на участке I, уменьшение крутизны кривых на участке II и смещение $E_{t}$ вверх по шкале $E_{\sim}$, когда $x$ в композите возрастает (рис. 4).

Увеличение с $x$ потерь $\operatorname{tg} \delta$ в полях, меньших и больших, чем $E_{t}$, обусловлено ростом концентрации точечных дефектов, относительно которых происходит движение сегнетоэлектрических доменных границ под действием измерительного поля. С ростом концентрации дефектов, в роли которых выступают ионы $\mathrm{Ni}$, попадающие в PZT в процессе напыления композита, возрастает энергия взаимодействия точечных дефектов с доменными границами, а с ней и поле $E_{t}$. Энергия взаимодействия в PZT имеет некоторое распределение по значениям, поэтому $\operatorname{tg} \delta$ при $E_{\sim}>E_{t}$ возрастает плавно, а не скачком, принимая максимальные величины.

Подтверждением того, что ионы Ni могут служить точечными дефектами, является смещение точки Кюри PZT в композите к низким температурам по отношению к точке Кюри PZT, обнаруженное на температурных зависимостях диэлектрической проницаемости $\varepsilon$ композита разного состава (рис. 5).

Понижение температуры для разупорядочения полярного состояния PZT в композите свидетельствует об уменьшении действия внутреннего поля на сегнетоактивные ионы в элементарной ячейке PZT, что, в свою очередь, имеет место в результате замещения атомов сегнетоэлектрической фазы атомами $\mathrm{Ni}$ из магнитной фазы, имеющими больший ионный радиус. Как следует из сопоставления ионных радиусов атомов $\mathrm{Ni}$ и $\mathrm{Pb}$, $\mathrm{Sr}, \mathrm{Na}, \mathrm{Bi}, \mathrm{Zr}$, Ti, в решетке PZT замещаются только атомы Ti.

Для проверки предположения о вкладе динамики сегнетоэлектрических доменных границ в диэлектрические потери была проведена работа по изучению зависимостей $\operatorname{tg} \delta\left(E_{\sim}\right)$ для образца композита, помещенного в постоянное электрическое поле разной напряженности (рис. 6).

Постоянное электрическое поле $E_{=}$„связывает“ сегнетоэлектрические домены, вследствие чего число до-

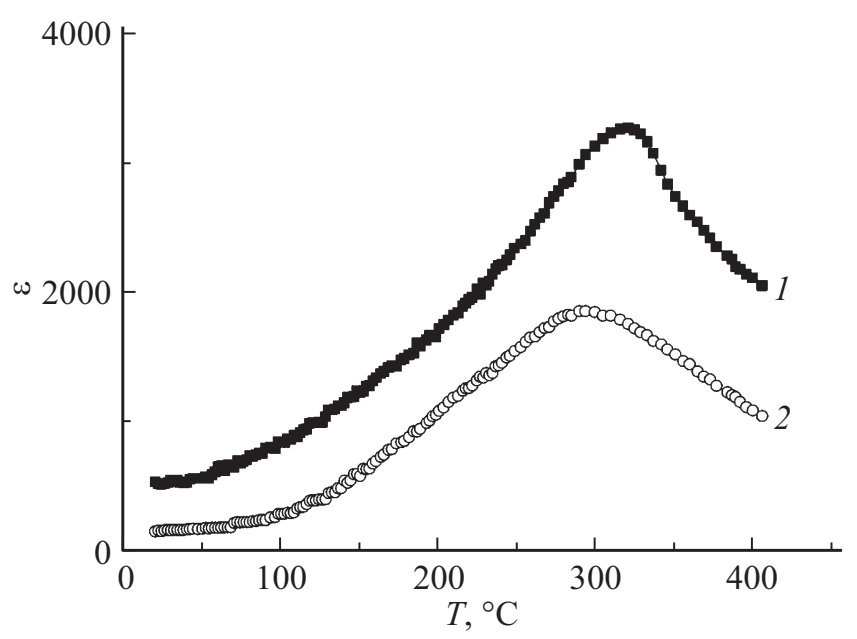

Рис. 5. Температурные зависимости $\varepsilon$ при частоте $1 \mathrm{kHz}$ и напряженности $E_{\sim}=0.7 \cdot 10^{5} \mathrm{~V} / \mathrm{m}$ для образцов композита $(x) \mathrm{Ni}-(1-x)$ PZT с разным $x: 1-0,2-0.1$.

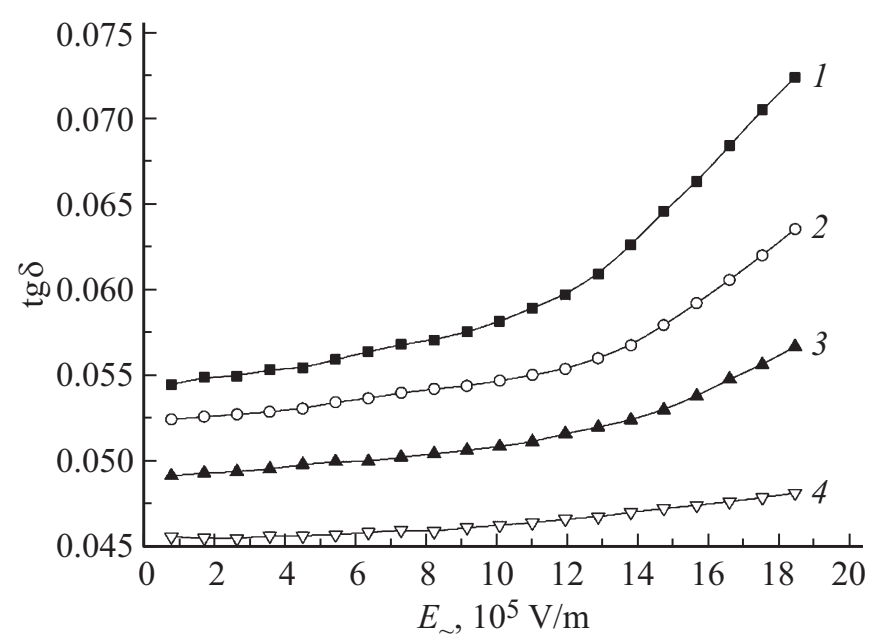

Рис. 6. Амплитудные зависимости $\operatorname{tg} \delta$ для образца композита $(x) \mathrm{Ni}-(1-x)$ PZT с $x=0.05$ при частоте $1 \mathrm{kHz}$, температуре $20^{\circ} \mathrm{C}$ и разных напряженностях $E_{=}, 10^{5} \mathrm{~V} / \mathrm{m}: 1-0,2-5$, $3-10,4-15$. 


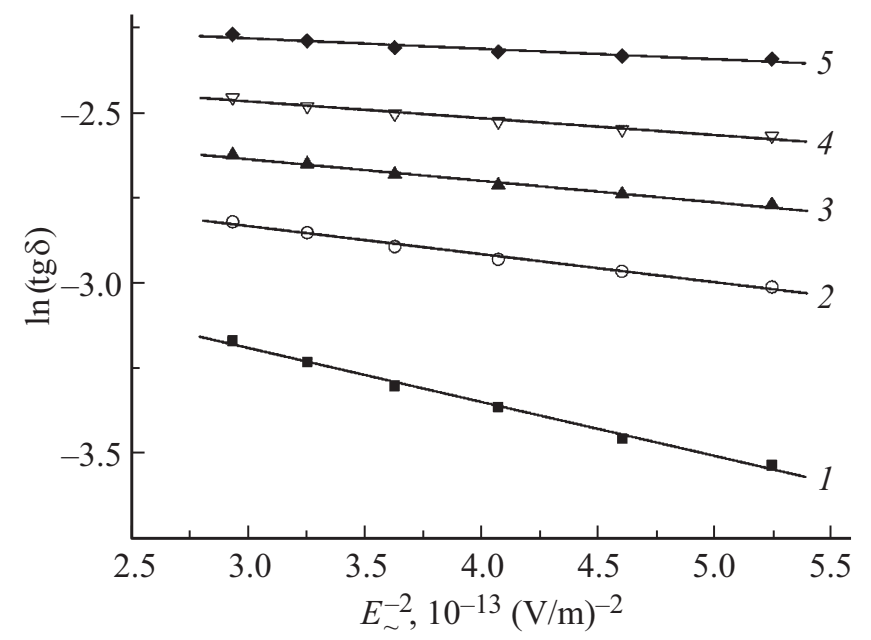

Рис. 7. Зависимости $\ln (\operatorname{tg} \delta)$ от $E_{\sim}^{-2}$ (в области значений $E_{\sim}>E_{t}$ ) при частоте $1 \mathrm{kHz}$ и температуре $20^{\circ} \mathrm{C}$ для образцов композита $(x) \mathrm{Ni}-(1-x)$ PZT с разным $x: 1-0,2-0.02$, $3-0.05,4-0.07,5-0.1$.

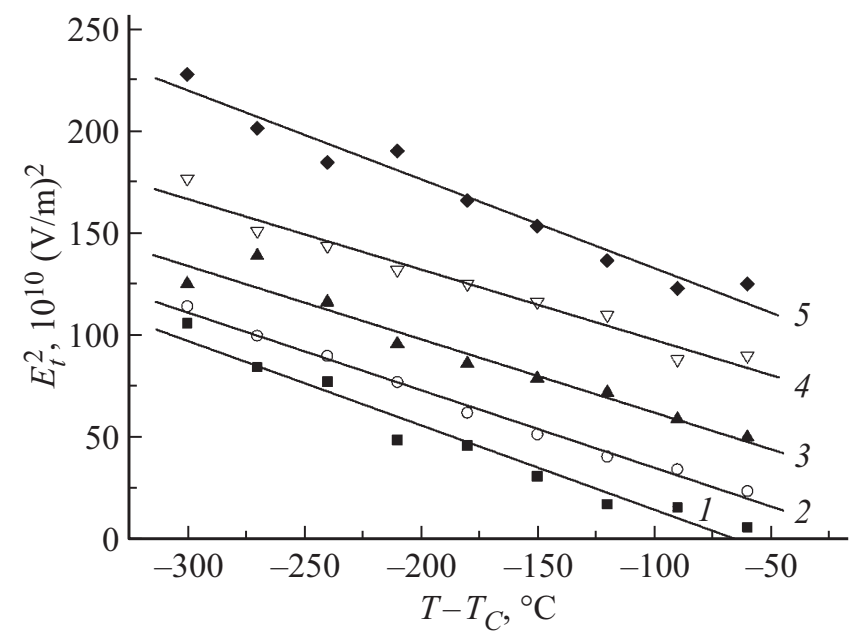

Рис. 8. Зависимости $E_{t}^{2}$ от $T-T_{C}$ при частоте $1 \mathrm{kHz}$ для образцов композита $(x) \mathrm{Ni}-(1-x) \mathrm{PZT}$ с разным $x: 1-0$, $2-0.02,3-0.05,4-0.07,5-0.1$.

менов, участвующих в переключении переменным измерительным полем, снижается. В результате с ростом $E_{=}$ потери $\operatorname{tg} \delta$ уменьшаются и $E_{t}$ увеличивается, что находится в хорошем согласии с доменным механизмом потерь.

В пользу доменного механизма свидетельствуют также следующие доказательства.

1. В области значений $E_{\sim}>E_{t}$ экспериментальные кривые $\operatorname{tg} \delta\left(E_{\sim}\right)$ удовлетворительно описываются полученным в рамках доменного механизма выражением

$$
\operatorname{tg} \delta=\frac{k}{E_{\sim}} \exp \left(-\frac{g^{2}}{E_{\sim}^{2}}\right),
$$

где $k$ и $g-$ коэффициенты, не зависящие от $E_{\sim}$.
Это проиллюстрировано линейными зависимостями $\ln (\operatorname{tg} \delta)$ от $E_{\sim}^{-2}$ на рис. 7, которые были установлены с использованием экспериментальных данных на рис. 4, выражения (1) и учетом в (1) гораздо более слабой зависимости предэкспоненциального множителя от $E_{\sim}$, чем $\exp \left(-\frac{g^{2}}{E_{\sim}^{2}}\right)$.

2. Зависимости $E_{t}^{2}$ от $T-T_{C}$ (рис. 8), построенные на основе экспериментальных зависимостей $\operatorname{tg} \delta\left(E_{\sim}\right)$ при разных температурах для образцов композита $(x) \mathrm{Ni}-(1-x) \mathrm{PZT}$, подтверждают предсказанную моделью линейную связь между $E_{t}$ и $\left(T-T_{C}\right)^{1 / 2}$.

3. Сила закрепления доменной границы точечным дефектом $f_{i}$, рассчитанная в рамках доменного механизма, по порядку величины совпадает с $f_{i}$, оцененной на основе уравнения электростатики.

Применительно к доменному механизму потерь [7]:

$$
f_{i}=2 P_{s} \bar{S} g,
$$

где $P_{s}-$ спонтанная поляризация; $\bar{S}=a^{2}-$ средняя площадь участка доменной границы, свободного от дефектов; $a$ - параметр элементарной ячейки.

Подставив в формулу (2) $P_{s}=23 \mu \mathrm{C} / \mathrm{cm}^{2} \quad$ [16], $a=4 \cdot 10^{-8} \mathrm{~cm}$ и величину коэффициента $g=12567 \mathrm{~V} / \mathrm{cm}$, найденного по углу наклона прямой на экспериментальной зависимости $\ln (\operatorname{tg} \delta)$ от $E_{\sim}^{-2}$ (рис. 7) для $(x) \mathrm{Ni}-(1-x) \mathrm{PZT}$ с $x=0$, получили $f_{i}$, равную $9.2 \cdot 10^{-14} \mathrm{~N}$. Эта величина близка к величине $f_{i}$, оцененной с использованием уравнения электростатики

$$
f_{i} \approx 2 U / d
$$

где $U$ - энергия взаимодействия точечного дефекта с доменной границей; $d$ - толщина доменной границы.

Расчет $f_{i}$ по формуле (3) при $U \sim 10^{-3} \mathrm{eV}[15]$ и $d=10^{-6} \mathrm{~cm}[17]$ дает значение $3.2 \cdot 10^{-14} \mathrm{~N}$.

4. Напряженность порогового поля пропорциональна концентрации точечных дефектов в образце.

Таким образом, совокупность экспериментальных фактов и численные оценки свидетельствуют о том, что амплитудные зависимости диэлектрических потерь в тонкопленочном наногранулированном композите $(x) \mathrm{Ni}-(1-x)$ РZT объясняются в рамках доменного механизма. Амплитудные зависимости для значений напряженности переменного электрического поля, больших значений напряженности порогового поля, описываются экспоненциальной функцией; $E_{t}^{2}$ изменяется с $T-T_{C}$ по линейному закону, а между напряженностью порогового поля и концентрацией точечных дефектов в образце имеет место прямая корреляция, вследствие чего $E_{t}$ можно использовать как один из индикаторов состояния доменной структуры сегнетоэлектрической компоненты композита.

\section{Финансирование работы}

Работа выполнена при финансовой поддержке проекта РНФ № 17-72-20105. 


\section{Конфликт интересов}

Авторы заявляют, что у них нет конфликта интересов.

\section{Список литературы}

[1] Handbook of thin-film deposition processes and techniques: Principles, methods, equipment and applications / Ed. K. Seshan. N.Y., Norwich (2002). 629 c.

[2] O.O. Abegunde, E.T. Akinlabi, O.P. Oladijo, S. Akinlabi, A.U. Ude. AIMS Mater. Sci. 6, 174 (2019).

[3] H. Palneedi, V. Annapureddy, S. Priya, J. Ryu. Actuators 5, 1 (2016).

[4] J.-G. Wan, Y. Weng, Y. Wu, Z. Li, J.-M. Liu, G. Wang. Nanotechnology 18, 465708 (2007).

[5] L.-V. Lich, T. Shimada, K. Miyata, K. Nagano, J. Wang, T. Kitamura. Appl. Phys. Lett. 107, 232904 (2015).

[6] М.Е. Адамова, Е.А. Жуков, А.В. Каминский. Изв. вузов. Приборостроение 62, 261 (2019).

[7] С.А. Гриднев, Б.М. Даринский, В.М. Попов, Л.А. Шувалов. ФТT 28, 2009 (1986).

[8] Л.Н. Коротков, Т.Н. Короткова. Изв. РАН. Сер. физ. 77, 1154 (2013).

[9] В.В. Волков, В.А. Боков. ФТТ 50, 193 (2008).

[10] В.С. Герасимчук, А.А. Шитов. ФТТ 54, 79 (2012).

[11] С.А. Флерова, И.Е. Чупис. Изв. РАН. Сер. физ. 57, 20 (1993).

[12] S.A. Gridnev, A.A. Kamynin, A.S. Shportenko, P.V. Kulakov. Ferroelectrics 501, 187 (2016).

[13] A.V. Kalgin. Ferroelectrics 561, 1 (2020).

[14] С.А. Гриднев, В.М. Попов, Л.А. Шувалов, В.Н. Нечаев. ФТT 27, 3 (1985).

[15] Л.Н. Камышева, О.М. Сердюк, С.Н. Дрождин, О.А. Зайцева. ФТТ 32, 1667 (1990).

[16] Ю.В. Подгорный, А.С. Вишневский, К.А. Воротилов, П.П. Лавров, А.Н. Ланцев. Микроэлектроника 43, 468 (2014).

[17] А.С. Сидоркин. Доменная структура в сегнетоэлектриках и родственных материалах. Физматлит, М. (2000). 240 с.

Редактор Ю.Э. Китаев 